\title{
Identification of Galectin-1 as a novel biomarker in nasopharyngeal carcinoma by proteomic analysis
}

\author{
CAN-E TANG ${ }^{1,3}$, TAN TAN $^{4}$, CUI LI $^{1}$, ZHU-CHU CHEN ${ }^{1}$, LIN RUAN $^{1}$, HONG-HAN WANG $^{2}$, \\ $\mathrm{TAO}^{3} \mathrm{SU}^{3}$, PENG-FEI ZHANG ${ }^{1}$ and ZHI-QIANG XIAO${ }^{1}$ \\ ${ }^{1}$ Key Laboratory of Cancer Proteomics of Chinese Ministry of Health, ${ }^{2}$ Department of Otolaryngology and \\ ${ }^{3}$ Medicine Research Center, Xiangya Hospital, Central South University, Changsha 410008; ${ }^{4}$ Department \\ of Clinical Laboratory, The First People's Hospital of Chenzhou, Hunan Province 423000, P.R. China
}

Received February 24, 2010; Accepted April 27, 2010

DOI: $10.3892 /$ or_00000884

\begin{abstract}
Nasopharyngeal carcinoma (NPC) is one of the most common malignant tumors in southern China and Southeast Asia. It is characterized as a multistep process involved in multiple genetic and epigenetic events. The mechanism of carcinogenesis still needs to be further clarified. In this study, two-dimensional gel electrophoresis, matrix-assisted laser desorption/ionization time of flight mass spectrometry (MALDI-TOF-MS), RT-PCR, Western blot and immunohistochemical (IHC) analyses were used to detect Galectin-1 expression in NPC compared with normal nasopharyngeal epithelial tissues (NNET). We found that Galectin-1 was expressed at a significantly higher level in NPC compared with NNET. Our results indicated that high expression level of Galectin-1 might correlate with the development of NPC and Galectin-1 may serve as a potential diagnostic marker or therapeutic target for NPC.
\end{abstract}

\section{Introduction}

NPC is a disease with remarkable racial and geographic distribution, which is one of the most common malignant tumors in southern China and Southeast Asia. The incidence rate is about $25-50$ per 100,000 person year and 100 -fold higher than that in the Western world $(1,2)$. With the advances in NPC study, many NPC-related molecules have been reported, such as serum antibodies against various EBV proteins (3), cathepsin D (4), stathmin 14-3-3, Annexin I (5), serum amyloid A (6), Bmi-1 (7) and Met protein (8). However, the molecular basis of NPC is still unclear. A

Correspondence to: Professor Zhi-Qiang Xiao, Key Laboratory of Cancer Proteomics of Chinese Ministry of Health, Xiangya Hospital, Central South University, Changsha 410008, P.R. China E-mail: tcezj@yahoo.com.cn

Key words: nasopharyngeal carcinoma, Galectin-1, proteomics, biomarker better understanding of the molecular basis of NPC is fundamental for developing more effective diagnostic, prognostic, treatment and prevention approaches.

High-throughput technologies such as microarrays and proteomics offer the potential ability to find alterations previously unidentified in NPC. Analyses for gene expression profiles of NPC with a cDNA array found that genes with aberrant expressions possibly contributed to the pathogenesis of NPC (9). Proteomics has provided new opportunities to uncover biomarkers and therapeutic targets for NPC as well as reveal the molecular mechanism underlying this disease. Using tissue samples from patients may be the most direct and persuasive way to find biomarkers and therapeutic targets for cancers by a proteomic approach.

In the present study, 2-DE and mass spectrometry (MS) were used to identify differential expression proteins between NPC and NNET samples. The differential expression of Galectin-1 was confirmed significantly up-regulated in NPC compared with NNET by RT-PCR and Western blot analysis. Our data will facilitate the better understanding of NPC carcinogenesis and reveal the function of Galectin-1 in NPC. Investigation of protein that occurs during carcinogenesis can provide new insights into the pathogenesis of cancer and is useful in developing new tumor biomarkers for the diagnosis and treatment of the disease.

\section{Materials and methods}

Materials and chemicals. Immobiline pH-gradient (IPG) DryStrips (pH 3-10, length $24 \mathrm{~cm}$ ), IPG buffer (pH 3-10), DryStrip cover fluids, thiourea, urea, CHAPS, DTT, Pharmalyte ( $\mathrm{pH} 3-10)$, bromophenol blue, Bis, TEMED, Coomassie Brilliant Blue G-250, molecular weight marker, Tris-base, SDS, glycine, horseradish peroxidase-conjugated goat anti-rabbit and anti-mouse IgG, and the enhanced chemiluminescence (ECL) system were purchased from Amersham Biosciences (Stockholm, Sweden). Sequencinggrade modified trypsin was obtained from Promega (Madison, WI, USA). PVDF membrane was obtained from Millipore (Boston, MA, USA). Polyclonal rabbit anti-human Galectin-1 antibody was from Santa Cruz Biotechnology (Santa Cruz, CA, USA). 
Tissue samples. Thirty-four cases of fresh undifferentiated NPC tissues and 20 cases of fresh NNET from healthy individuals were obtained from the First and Third XiangYa Hospital of Central South University, China. Among them, 10 cases of tissues selected randomly from each group were performed to separate proteins for $2 \mathrm{D}$ analysis, the remaining were used for the following validation. Informed consent was obtained from all patients before collection of the specimens, which were frozen in liquid nitrogen immediately after surgical removal. The study was approved by the hospital ethics committee, and all patients in the study gave their consent before tissue donation.

Two-dimensional electrophoresis. 2-DE was performed to separate proteins as previously described by us (10). Briefly, $600 \mu \mathrm{g}$ of protein samples were diluted to $450 \mu \mathrm{l}$ with a rehydration solution [7 mol/1 urea, $2 \mathrm{~mol} / 1$ thiourea, $0.2 \%$ DTT, $0.5 \%(\mathrm{v} / \mathrm{v}) \mathrm{pH} 3-10$ IPG buffer, and trace bromophenol blue], and applied to IPG strips (pH 3-10 L, $24 \mathrm{~cm}$ ) by $14 \mathrm{~h}$ rehydration at $30 \mathrm{~V}$. The proteins were focused successively for $1 \mathrm{~h}$ at $500 \mathrm{~V}, 1 \mathrm{~h}$ at $1000 \mathrm{~V}$ and $8.5 \mathrm{~h}$ at $8000 \mathrm{~V}$ to give a total of $68 \mathrm{kVh}$ on an IPGphor (Amersham Biosciences). Focused IPG strips were equilibrated for $15 \mathrm{~min}$ in a solution (6 mol/1 urea, 2\% SDS, 30\% glycerol, $50 \mathrm{mmol} / 1$ Tris- $\mathrm{HCl}$, $\mathrm{pH} 8.8$ and 1\% DTT), and then for an additional $15 \mathrm{~min}$ in the same solution except that DTT was replaced by $2.5 \%$ iodoacetamide. After equilibration, SDS-PAGE was performed on Ettan DALT II system (Amersham Biosciences). After SDS-PAGE, the Blue Silver staining method, a modified Neuhoff's colloidal Coomassie Brilliant Blue G-250 stain, was used to visualize the protein spots in the 2-DE gels. Triplicate gels were made for each conditioned medium.

Image analysis. The stained 2-DE gels were scanned with Magic-Scan software on Image-scanner (Amersham Biosciences), and analyzed using PDQuest system (Bio-Rad Laboratories, Hercules, CA, USA) according to the protocols provided by the manufacturer. To minimize the contribution of experimental variations, three separate gels were prepared for each conditioned medium. The gel spot pattern of each gel was summarized in a standard manner after spot matching. Thus, we obtained one average gel for each conditioned medium. Spot intensities were quantified by calculation of spot volume after normalization of the image using the total spot volume normalization method multiplied by the total area of all the spots.

Mass spectrometry analysis. All the differential protein spots were excised from stained gels using a punch, and in-gel trypsin digestion was performed as previously described by us (11). The tryptic peptide was mixed with a CCA matrix solution. The mixture $(1 \mu \mathrm{l})$ was analyzed with a Voyager System DE-STR 4307 MALDI-TOF Mass Spectrometer (ABI, Foster City, CA, USA) to get a peptide mass fingerprint (PMF). In PMF map database searching, Mascot Distiller was used to obtain the monoisotopic peak list from the raw mass spectrometry files. Peptide matching and protein searches against the Swiss-Prot database were performed using the Mascot search engine (http://www. matrixscience.com/) with a mass tolerance of $\pm 50 \mathrm{ppm}$.
Reverse transcription-polymerase chain reaction (RT-PCR). Twenty-four cases of fresh NPC and 10 cases of NNET tissues were homogenized to powder using liquid nitrogen and then divided into two groups. The total RNA was isolated from one group of tissues by TRIzol (Takara, Dalian, China) according to the protocol supplied by the manufacturers. The traced DNA had been removed by DNase I treatment in total RNA. cDNA synthesis and RT-PCR were performed as previously described (12). The sequences of the primers used in PCR amplification were as follows: 5'CAAACCTGGAGAGTGCCTTC-3' and 5'-GATGCACAC CTCTGCAACAC-3' for Galectin-1; 5'-GTCAGTGGT GGACCTGACCT-3' and 5'-TGAGGAGGGGAGATTCA GTG-3' for GAPDH (a gene used for normalization). The Galectin-1 PCR conditions were as follows: $5 \mathrm{~min}$ at $96^{\circ} \mathrm{C}$ for denaturation, followed by 27 cycles of $30 \mathrm{sec}$ at $95^{\circ} \mathrm{C}, 30 \mathrm{sec}$ at $57^{\circ} \mathrm{C}$ and $30 \mathrm{sec}$ at $72^{\circ} \mathrm{C}$. GAPDH was amplified as follows: $5 \mathrm{~min}$ at $96^{\circ} \mathrm{C}$ for denaturation, followed by 28 cycles of $30 \mathrm{sec}$ at $95^{\circ} \mathrm{C}, 30 \mathrm{sec}$ at $55^{\circ} \mathrm{C}$ and $30 \mathrm{sec}$ at $72^{\circ} \mathrm{C}$. PCR products were resolved in $2 \%$ agarose gels containing ethidium bromide.

Western blot analysis. The remaining powder group tissues were respectively dissolved in lysis buffer [150 $\mathrm{mM} \mathrm{NaCl}$, $50 \mathrm{mM}$ Tris-Cl, pH 8.0, 0.1\% Nonidet 40 (NP-40), $1 \mathrm{mM}$ PMSF, $25 \mu \mathrm{g} / \mathrm{ml}$ aprotinin, $25 \mu \mathrm{g} / \mathrm{ml}$ leupeptin], votexed and incubated at room temperature for $2 \mathrm{~h}$. The mixture was then centrifuged at $15000 \mathrm{rpm}$ for $30 \mathrm{~min}$ at $4^{\circ} \mathrm{C}$. The supernatant was used as the total protein solution. The concentration of the lysate was assayed with the Bradford assay (Bio-Rad Laboratories). Western blot analysis was performed as previously described (13). Briefly, $100 \mu \mathrm{g}$ of total protein was separated on a $12 \%$ SDS-PAGE gel prior to transfer onto a PVDF membrane. After blocking with 5\% milk in TBS/0.2\% Tween-20 (TBS-T) for $1 \mathrm{~h}$ at room temperature, the membrane was incubated with rabbit anti-mouse Galectin-1 antibody (1:500 dilution) (Cell Signaling Technology, Inc., Beverly, MA) for $1 \mathrm{~h}$ at room temperature, followed by incubation with horseradish peroxidase (HRP)-conjugated goat anti-rabbit IgG secondary antibody (1:10000 dilution, Amersham Biosciences) for $1 \mathrm{~h}$ at room temperature. Detection of B-actin (Sigma, 1:4000 dilution) was used as loading control. The reactions were visualized using an enhanced chemiluminescence detection system (ECL, Amersham Biosciences). Signals on the blots were visualized by autography.

Immunohistochemical (IHC) analysis. Thirty-two cases of NPC and 10 cases of NNET (none of them were analyzed using 2-DE) were used to measure the distribution and abundance of the protein Galectin-1 by a standard immunohistochemical technique. Paraffin blocks were cut into $4-\mu \mathrm{m}-$ thick sections. The sections were then deparaffinized in xylene and rehydrated in graded alcohol concentrations. Non-specific binding was blocked by pre-incubation with blocking solution for $5 \mathrm{~min}$ followed by incubation overnight at $4^{\circ} \mathrm{C}$ with rabbit anti-mouse Galectin-1 (1:200 dilution). The sections were then washed 3 times with phosphatebuffered solution (PBS) for $5 \mathrm{~min}$ each and then incubated with HRP-conjugated goat anti-rabbit $\operatorname{IgG}$ (1:200 dilution) for $30 \mathrm{~min}$ at room temperature. The sections were then 

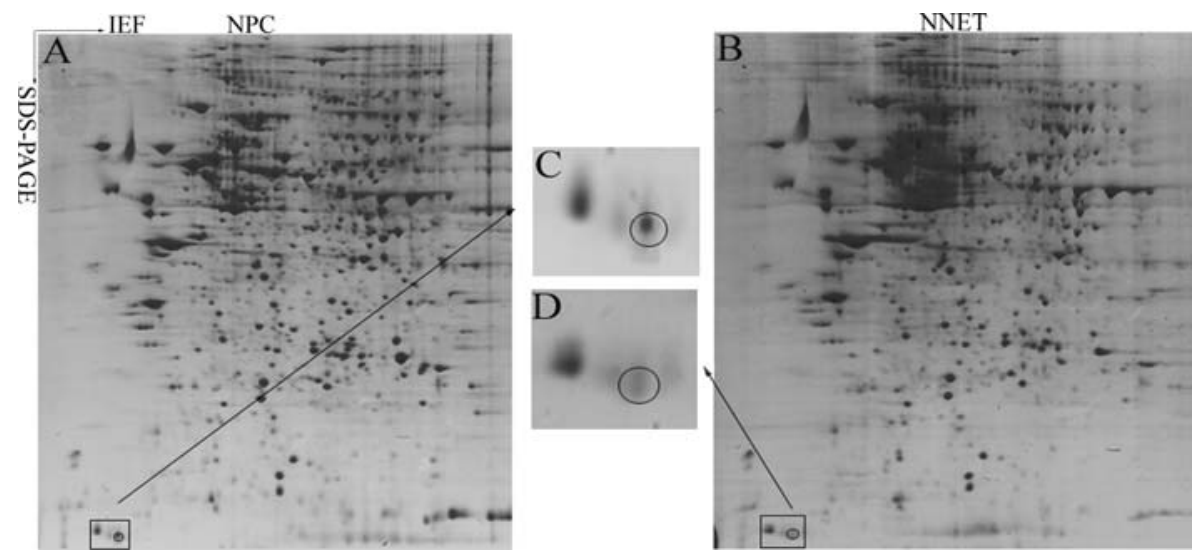

Figure 1. Galectin-1 expression detected by two-dimensional gel electrophoresis. (A) and (C) from NPC. (B) and (D) from NNET. Independent experiments were performed 3 times for each group.

A

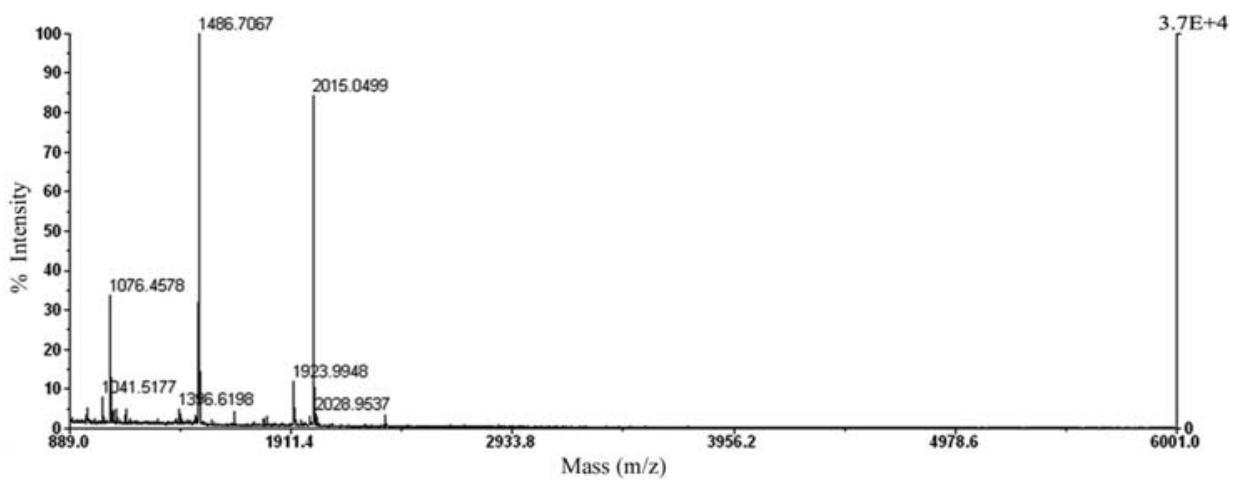

B 1 MACGLVASNL NLKPGECLRV RGEVAPDAKS FVLNLGKDSN NLCLHFNPRF

51 NAHGDANTIV CNSKDGGAWG TEQREAVFPF QPGSVAEVCI TFDQANLTVK

101 LPDGYEFKFP NRLNLEAINY MAADGDFKIK CVAFD

C Probability Based Mowse Score

Protein score is $-10^{*} \log (\mathrm{P})$, where $\mathrm{P}$ is the probability that the observed match is a random event. Protein scores greater than 56 are significant $(\mathrm{p}<0.05)$

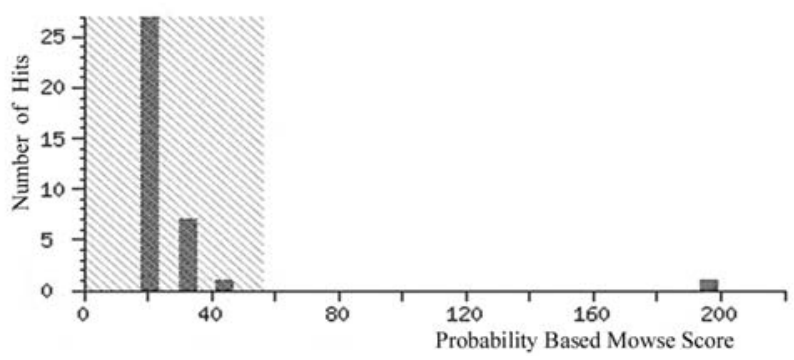

Figure 2. Mass spectra of MALDI TOF-MS of the spot identified as Galectin-1. The protein sequence and the score of Galectin-1 protein spot by database query is shown, the matched peptides are underlined.

washed with PBS and incubated with substrate-chromogen 3,3'-diaminobenzidine (DAB) reagent. Hematoxylin solution was then used to stain the nuclei. Negative controls without primary antibody were processed along with all the samples.

Statistical analysis. Statistical analysis was done by using SPSS (version 10.0). The significant difference of Galectin-1 expression between the tumor and normal tissues was determined by using the $t$ test or Mann-Whitney's U test. A difference of $\mathrm{P}<0.05$ was considered statistically significant. Results are expressed as means \pm standard deviation.

\section{Results}

2-DE maps of NPC and NNET. Proteins from 2 sets of pooled (10 samples/group) NPC and NNET were resolved by 2-DE, 

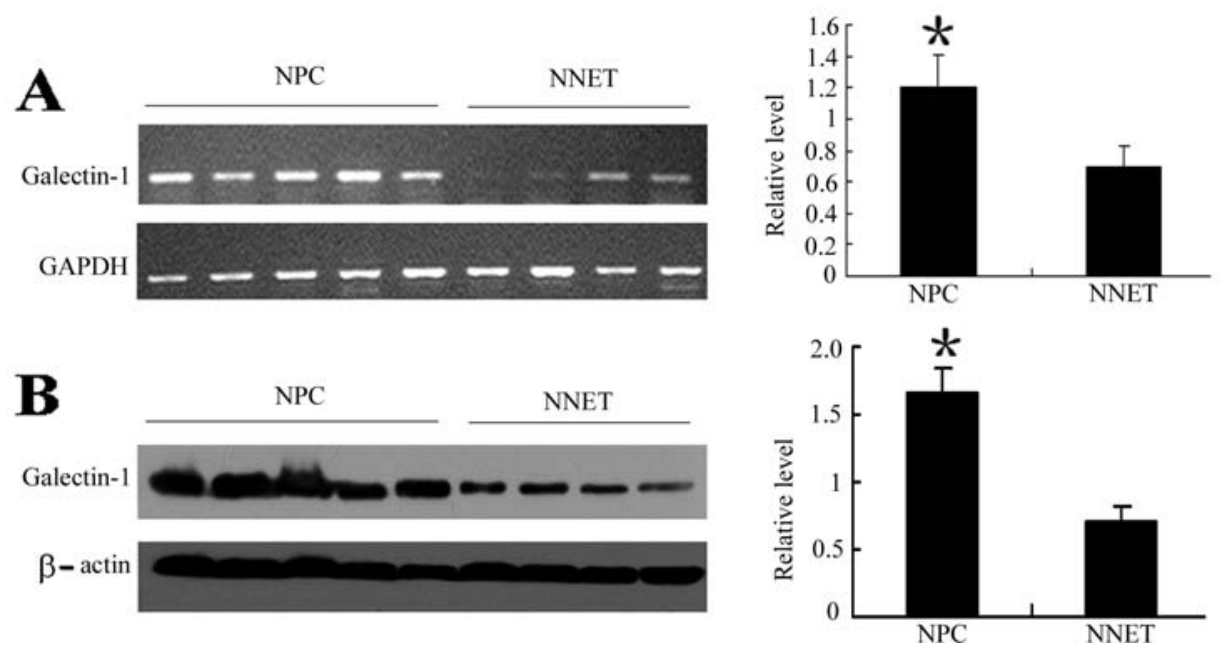

Figure 3. Representative results of RT-PCR and Western blot analysis of Galectin-1 in the NPC $(n=24)$ and NNET ( $n=10)$ tissues. (A) Left panel, RT-PCR analysis shows changes in the mRNA expression levels of Galectin-1 in NPC tissue (T) and NNET (N). Right panel, histogram shows the mRNA expression levels of Galectin-1 in each group as determined by densitometric analysis and normalized with GAPDH. (B) Left panel, Western blot analysis shows changes in the protein expression levels of Galectin-1 in NPC tissue (T) and NNET (N). Right panel, histogram shows the protein expression levels of Galectin-1 in each group as determined by densitometric analysis and normalized with $\beta$-actin.
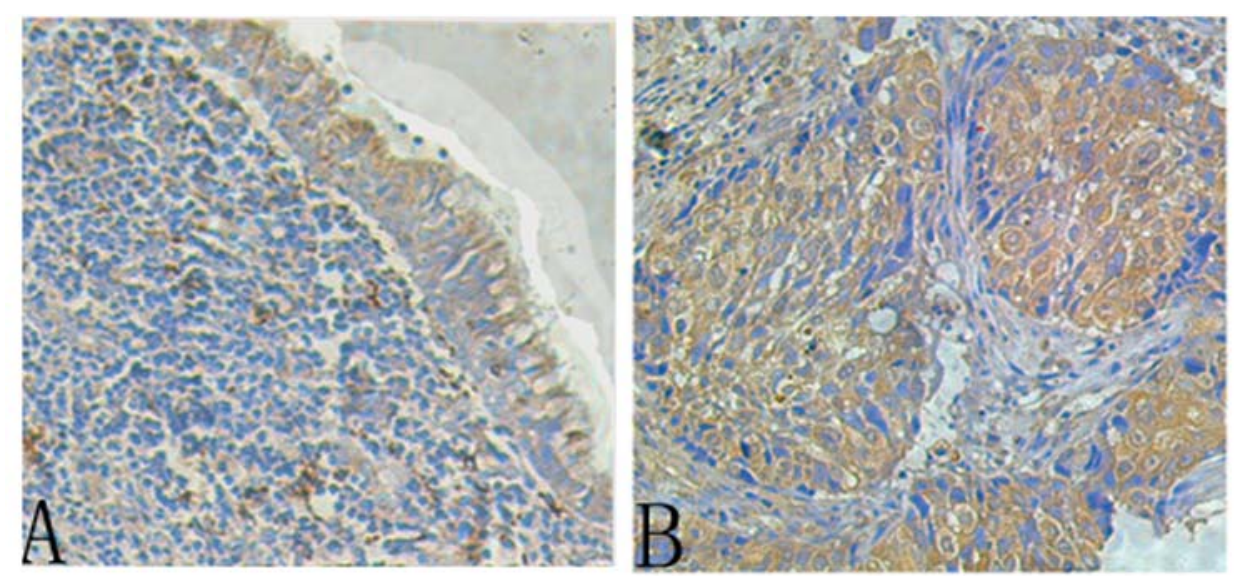

Figure 4. A representative result of Galectin-1 immunohistochemistry in NPC ( $n=32)$ and NNET $(n=10)$. (A) Strong staining of NPC tissue; (B) Weak staining of NNET. Original magnification, x200.

respectively, and stained with Coomassie Brilliant Blue. These experiments were repeated three times under identical experimental conditions and parameters to confirm reproducibility. Well-resolved and reproducible Coomassie Brilliant Bluestained 2-DE maps from NPC and NNET were obtained. The volume of the Galectin-1 protein spot derived from the NPC was obviously larger than that of the NNET tissues (Fig. 1).

Identification of Galectin-1 protein expression by MALDITOF MS. The differentially expressed protein spots were excised from Coomassie Brilliant Blue-stained gels and subjected to in-gel digestion with trypsin and analyzed by MALDI TOF-MS. We focused on an interesting differential protein spot, as shown in Fig. 1. It was analyzed by mass spectroscopy and indentified as Galectin-1. Galectin-1 received a protein score of 196 and has a MW of $15048 \mathrm{Da}$, a PI of 5.34 and accession no. IPI00219219 (Fig. 2).

Verification of Galectin-1 expression by RT-PCR and Western blot analysis. The Galectin-1 mRNA expression was evaluated
Table I. The difference of Galectin-1 expression among NNET and NPC.

\begin{tabular}{lcrrcr}
\hline & \multicolumn{3}{c}{ Galectin-1 staining } & & \\
\cline { 2 - 4 } Tissues & $0-2$ & $3-4$ & $5-6$ & Total & P-value \\
\hline NNET & 6 & 4 & 0 & 10 & $0.006^{\mathrm{a}}$ \\
NPC & 2 & 11 & 19 & 32 & \\
\hline
\end{tabular}

${ }^{\mathrm{a}} \mathrm{P}<0.01$ by Mann-Whitney U test.

by RT-PCR in the remaining 24 cases of fresh-frozen NPC tissues samples and 10 cases of NNET tissues samples. There was a statistically significant difference in Galectin-1 mRNA expression between NPC and NNET samples $(\mathrm{P}<0.05)$. Galectin-1 mRNA was up-regulated in NPC compared with NNET tissues (Fig. 3A). Western blotting was also performed to detect the Galectin-1 protein expression and the results 
were consistent with the RT-PCR and 2-DE results $(\mathrm{P}<0.05$, Fig. 3B). Both the RT-PCR and Western blot results indicated that overexpression of Galectin-1 might be related to development and progression of NPC, and the variables of Galectin-1 occurred at the transcription level.

IHC pattern of Galectin-1 expression. To examine the relevance of this finding to clinical NPC cancer, we used IHC to detect Galectin-1 in 32 cases of NPC and 10 cases of NNET. As shown in Fig. 4 and Table I, intense staining was detected in the tumor cells. In contrast, the overall density of Galectin- $1^{+}$cells in the sections from the NNET was significantly lower than that in NPC. The result also indicates the association of Galectin-1 gain with NPC occurence.

\section{Discussion}

NPC is one of the most common malignant tumors in Southern China and Southeast Asia (1). Although NPC is classified as a subtype of head and neck squamous cell carcinoma, the epidemiology, clinical characteristics, etiology and histopathology are unique. Therefore, early diagnosis, exact histologic grading and accurate prognostication of NPC are critical for guiding the treatment and improving the prognosis of NPC. Identification of new NPC biomarkers may be an important way to achieve these objectives.

A number of studies have recently identified multiple genetic and epigenetic alterations that occur in NPC. Differential proteomic analysis of tumor and normal tissues allows the identification of aberrantly expressed proteins in cancer which might provide key information for finding biomarkers for the diagnosis and treatment of cancer as well as an understanding of carcinogenesis (14). In this study, we focused on up-regulated protein Galectin-1 in cancer tissues.

Galectin-1 is a member of the carbohydrate binding protein family that shows affinity for $\beta$-galactosides. It has been reported to play an important role in interaction with p27, Ras, Raf and PI-3K (15-18). Galectin-1 is extracellularly expressed in many tissues including normal and pathological conditions, and its expression has been shown to be higher in colorectal, pancreatic and non-small cell lung cancer (19-22). However, there is no previous report on association between Galectin-1 and NPC.

Our current study showed that Galectin-1 expression level was significantly higher in NPC tissues. This observation was supported by 2-DE, MS, RT-PCR, Western blot and immunohistochemical analysis. The 2-DE and MS analysis showed that Galectin-1 protein expression was significantly higher in NPC than the control group. RT-PCR and Western blot analysis confirmed these results. The percentage of Galectin- $1^{+}$cells in NPC cell population was significantly higher than the control. These results provide new mechanistic insight into the occurrence of NPC.

In summary, Galectin-1 overexpression was observed in NPC tissues using a proteomic approach and may serve as a novel biomarker for NPC. These findings suggest that Galectin-1 might have clinical value in predicting the prognosis of NPC, and identifying NPC patients who are at high risk of progression.

\section{Acknowledgements}

This study was supported by National Nature Science Foundation of China (30973290), Outstanding Scholars of New Era from Ministry of Education of China (NECT-070861), Science and Technology Plan Project of Hunan Province (08FJ3182).

\section{References}

1. Yu MC and Yuan JM: Epidemiology of nasopharyngeal carcinoma. Semin Cancer Biol 12: 421-429, 2002.

2. McDermott AL, Dutt SN and Watkinson JC: The aetiology of nasopharyngeal carcinoma. Clin Otolaryngol Allied Sci 26: 82-92, 2001.

3. Wong MM, Lye MS, Cheng HM and Sam CK: Epstein-Barr virus serology in the diagnosis of nasopharyngeal carcinoma. Asian Pac J Allergy Immunol 23: 65-67, 2005.

4. Cheng AL, Huang WG, Chen ZC, Zhang PF, Li MY, Li F, Li JL, Li C, Yi H, Peng F, Duan CJ and Xiao ZQ: Identification of cathepsin D as a biomarker for differentiation and prognosis of nasopharyngeal carcinoma by laser capture microdissection and proteomic analysis. J Proteome Res 7: 2415-2426, 2008.

5. Cheng AL, Huang WG, Chen ZC, Peng F, Zhang PF, Li MY, $\mathrm{Li} \mathrm{F}$, Li JL, Li C, Yi H, Yi B and Xiao ZQ: Identification of novel nasopharyngeal carcinoma biomarkers by laser capture microdissection and proteomic analysis. Clin Cancer Res 14: 435-445, 2008.

6. Diamandis EP: Identification of serum amyloid a protein as a potentially useful biomarker for nasopharyngeal carcinoma. Clin Cancer Res 10: 5293-5294, 2004.

7. Song LB, Zeng MS, Liao WT, Zhang L, Mo HY, Liu WL, Shao JY, Wu QL, Li MZ, Xia YF, Fu LW, Huang WL, Dimri GP, Band V and Zeng YX: Bmi-1 is a novel molecular marker of nasopharyngeal carcinoma progression and immortalizes primary human nasopharyngeal epithelial cells. Cancer Res 66: 6225-6232, 2006.

8. Qian CN, Guo X, Cao B, Kort EJ, Lee CC, Chen J, Wang LM, Mai WY, Min HQ, Hong MH, Vande WG, Resau JH and Teh BT: Met protein expression level correlates with survival in patients with late-stage nasopharyngeal carcinoma. Cancer Res 62: 589-596, 2002.

9. Sriuranpong V, Mutirangura A, Gillespie JW, Patel V, Amornphimoltham P, Molinolo AA, Kerekhanjanarong V, Supanakorn S, Supiyaphun P, Rangdaeng S, Voravud N and Gutkind JS: Global gene expression profile of nasopharyngeal carcinoma by laser capture microdissection and complementary DNA microarrays. Clin Cancer Res 10: 4944-4958, 2004.

10. Li C, Xiao Z, Chen Z, Zhang X, Li J, Wu X, Li X, Yi H, Li M, $\mathrm{Zhu} \mathrm{G}$ and Liang $\mathrm{S}$ : Proteome analysis of human lung squamous carcinoma. Proteomics 6: 547-558, 2006.

11. Yang F, Xiao ZQ, Zhang XZ, Li C, Zhang PF, Li MY, Chen Y, Zhu GQ, Sun Y, Liu YF and Chen ZC: Identification of tumor antigens in human lung squamous carcinoma by serological proteome analysis. J Proteome Res 6: 751-758, 2007.

12. McCabe CJ, Khaira JS, Boelaert K, Heaney AP, Tannahill LA, Hussain S, Mitchell R, Olliff J, Sheppard MC, Franklyn JA and Gittoes NJ: Expression of pituitary tumour transforming gene (PTTG) and fibroblast growth factor-2 (FGF-2) in human pituitary adenomas: relationships to clinical tumour behaviour. Clin Endocrinol 58: 141-150, 2003.

13. Chen Y, Tang CE, Ouyang GL, Ruan L, Li MY, Zhang PF, Li C, Yi H, Peng F, Li JL, Chen ZC and Xiao ZQ: Identification of RKIP as a differentially tyrosine-phosphorylated protein in nasopharyngeal carcinoma and normal nasopharyngeal epithelial tissues by phosphoproteomic approach. Med Oncol 26: 463-470, 2009.

14. Reymond MA and Schlegel W: Proteomics in cancer. Adv Clin Chem 44: 103-142, 2007.

15. Ingrassia L, Camby I, Lefranc F, Mathieu V, Nshimyumukiza P, Darro F and Kiss R: Anti-galectin compounds as potential anticancer drugs. Curr Med Chem 13: 3513-3527, 2006.

16. Camby I, Le MM, Lefranc F and Kiss R: Galectin-1: a small protein with major functions. Glycobiology 16: R137-R157, 2006. 
17. Fischer C, Sanchez-Ruderisch H, Welzel M, Wiedenmann B, Sakai T, Andre S, Gabius HJ, Khachigian L, Detjen KM and Rosewicz S: Galectin-1 interacts with the $\{$ alpha\} 5 beta 1 fibronectin receptor to restrict carcinoma cell growth via induction of p21 and p27. J Biol Chem 280: 37266-37277, 2005.

18. Elad-Sfadia G, Haklai R, Ballan E, Gabius HJ and Kloog Y Galectin-1 augments Ras activation and diverts Ras signals to Raf-1 at the expense of phosphoinositide 3-kinase. J Biol Chem 277: 37169-37175, 2002.

19. Szoke T, Kayser K, Baumhakel JD, Trojan I, Furak J, Tiszlavicz L, Horvath A, Szluha K, Gabius HJ and Andre S: Prognostic significance of endogenous adhesion/growthregulatory lectins in lung cancer. Oncology 69: 167-174, 2005 .
20. Grutzmann R, Pilarsky C, Ammerpohl O, Luttges J, Bohme A, Sipos B, Foerder M, Alldinger I, Jahnke B, Schackert HK, Kalthoff H, Kremer B, Kloppel G and Saeger HD: Gene expression profiling of microdissected pancreatic ductal carcinomas using high-density DNA microarrays. Neoplasia 6: 611-622, 2004.

21. Shen J, Person MD, Zhu J, Abbruzzese JL and Li D: Protein expression profiles in pancreatic adenocarcinoma compared with normal pancreatic tissue and tissue affected by pancreatitis as detected by two-dimensional gel electrophoresis and mass spectrometry. Cancer Res 64: 9018-9026, 2004.

22. Gabius HJ, Andre S, Gunsenhauser I, Kaltner H, Kayser G, Kopitz J, Lahm H, Harms D, Szymas J and Kayser K: Association of galectin-1- but not galectin-3-dependent parameters with proliferation activity in human neuroblastomas and small cell lung carcinomas. Anticancer Res 22: 405-410, 2002. 